\title{
О КРИТЕРИЯХ И МЕТОДИКЕ ФОРМИРОВАНИЯ ИННОВАЦИОННОЙ КУЛЬТУРЫ СТУДЕНТОВ В ПРОЦЕССЕ ИЗУЧЕНИЯ АНГЛИЙСКОГО ЯЗЫКА
}

\author{
Хожсамуратов Рамил Ибрахимович \\ Каракалпакский государственный университет имени Бердаха, г. Нукус, Узбекистан
}

DOI: https://doi.org/10.31435/rsglobal_ws/28022020/6937

\section{ARTICLE INFO}

Received: 25 December 2019

Accepted: 12 February 2020

Published: 28 February 2020

\section{KEYWORDS}

adaptive level, innovative and informational culture, communication, creative level, reproductive level, reflection, heuristic level.

\begin{abstract}
An analysis of the scientific and theoretical literature indicates that the formation of an innovative culture of students, as well as modern pedagogical technologies in the formation of cognitive activity of students, has been studied quite extensively. However, innovative approaches in the process of learning English, the application of methods and tools aimed at the formation of cognitive activity during training sessions, have not been sufficiently studied or are fragmented. Therefore, the article raises one of the urgent problems, which requires a special study.
\end{abstract}

Citation: Хожамуратов Р. И. (2020) О Kriteriyah i Metodike Formirovaniya Innovacionnoj Kul'tury Studentov v Processe Izucheniya Anglijskogo Yazyka. World Science. 2(54), Vol.2. doi: 10.31435/rsglobal_ws/28022020/6937

Copyright: (C) 2020 Хожамуратов Р. И. This is an open-access article distributed under the terms of the Creative Commons Attribution License (CC BY). The use, distribution or reproduction in other forums is permitted, provided the original author(s) or licensor are credited and that the original publication in this journal is cited, in accordance with accepted academic practice. No use, distribution or reproduction is permitted which does not comply with these terms.

Актуальность исследования. Широкое применение современных лингводидактических технологий, принципов и содержания информационно-образовательной среды в обучении имеет особое значение в формировании у студентов информационной и инновационной культуры в процессе изучения английского языка на факультетах иностранных языков в системе высшего образования. Исходя из проведённых анализов научной литературы, в мировом сообществе формирование инновационной культуры обучающихся, является важным фактором устойчивого развития во всех сферах жизни общества и страны. В таких ведущих странах мира, как например, Сингапур, Корея, Англия, Германия, Российская Федерация подготовка специалистов обладающих информационной культурой, имеющих высокий уровень общеобразовательной и высшей профессиональной подготовки действуют профессионально в различных стандартных и нестандартных педагогических ситуациях, принимают правильные творческие решения в языковых проблемах.

В исследованиях, проводимых в ведущих высших образовательных учреждениях и научных центрах мирового масштаба, как Оксфордский, Кембриджский университеты в Великобритании, Чумбукский университет в Южной Корее, Фрайбургский университет в Германии, Московский государственный университет в России и другие высшие учебные заведения играют важную роль в формировании инновационной культуры у студентов будущих специалистов и реализации современного конкурентноспособного образования, особое значение придаётся проблемам создания инновационной культуры в процессе изучения английского языка, а также и внедрению требований международных образовательных стандартов. В современных исследованиях по педагогическим проблемам важное место занимает научный поиск, направленный на формирование педагогического профессионализма преподавателей путём развития модульно-кредитных образовательных требований.

В целях кардинального совершенствования системы высшего образования в Республике Узбекистан, коренного пересмотра содержания подготовки кадров в соответствии с приоритетными задачами социально-экономического развития страны, обеспечения 
необходимых условий для подготовки специалистов с высшим образованием на уровне международных стандартов, в Указе Президента Республики Узбекистан «Об утверждении концепции развития системы высшего образования Республики Узбекистан до 2030 года» отмечается: «повышение соотношения самостоятельной работы, получение самостоятельного образования у студентов, креативное и творческое мышление, формирование навыков предпринимательства, применение методик и технологий направленных на усиление компетенций учебного процесса, широкое применение в учебный процесс инновационных технологий, учебно-методических и учебных пособий отвечающих требованиям международных образовательных стандартов» ${ }^{1}$. Это в свою очередь совершенствует механизмы педагогической системы, индивидуализацию на основе цифровизации педагогического процесса, развитие дистанционного образования, вебинары, онлайнтехнологии «blended learning», «flipped classroom», направленные на развитие практических навыков по формированию познавательной деятельности студентов.

Формирование инновационной культуры в вузе неразрывно связано с формированием модели развивающейся, само актуализирующейся личности, к которой необходимо стремиться в процессе воспитания и обучения. Критерии профессионально-педагогической культуры определялись исходя из системного понимания культуры, выделения её структурных и функциональных компонентов, толковании культуры как процесса и результата творческого освоения и создания педагогических ценностей, технологий при профессионально-творческой самореализации личности педагога. Выделяют четыре уровня сформированности инновационной культуры студентов в процессе изучения английского языка: адаптивный, репродуктивный, эвристический, креативный.

Адаптивный уровень инновационной культуры характеризуется неустойчивым отношением педагога к педагогической реальности при изучении английского языка. Цели и задачи педагогической деятельности им определены в общем виде. К психологопедагогическим знаниям педагог безразличен, отсутствует система знаний, и нет готовности к их использованию в конкретных педагогических ситуациях. Профессионально-педагогическая деятельность строится по заранее отработанной схеме без использования творчества. Преподаватели, находящиеся на этом уровне, не проявляют активности в плане инновационного самосовершенствования, повышение квалификации осуществляют по необходимости, либо вообще отвергают.

Репродуктивный уровень предполагает склонность к устойчивому ценностному отношению к педагогической реальности: педагог более высоко оценивает роль инновационной культуры, проявляет стремление к установлению субъект-субъектных отношений между участниками педагогического процесса в процессе изучения английского языка, ему присущ более высокий индекс удовлетворенности педагогической деятельностью. При данном уровне развития инновационной культуры педагогом успешно решаются конструктивно-прогностические задачи, предполагающие целеполагание и планирование профессиональных действий. Творческая активность ограничивается производящей деятельностью, но уже возникают элементы поиска новых решений в стандартных педагогических ситуациях. Формируется педагогическая направленность потребностей, интересов и склонностей. Педагог осознает необходимость повышения квалификации.

Эвристический уровень проявления инновационной культуры характеризуется большей целенаправленностью, устойчивостью путей и способов профессиональной деятельности. На данном уровне инновационной культуры происходят изменения в структуре технологического компонента; на высоком уровне сформированное находятся умения решать оценочно-информационные и коррекционно-регулирующие задачи. Деятельность педагогов связана с постоянным поиском; они выделяют новые технологии обучения и воспитания, готовы передавать свой опыт другим. К предлагаемым формам повышения квалификации относятся избирательно, овладевают основными методами познания и анализа собственной личности и деятельности.

Креативный уровень характеризуется высокой степенью результативности педагогической деятельности, мобильностью психолого-педагогических знаний, утверждением

\footnotetext{
1 № УП - 5847 от 8 октября 2019 года «Об утверждении Концепции развития системы высшего образования Республики Узбекистан до 2030 года»/ Национальная информационная база законодательных документов, 09.10.2019 г., № 06/19/5847/3887.
} 
отношений сотрудничества и сотворчества со студентами и коллегами. Положительноэмоциональная направленность деятельности педагога стимулирует устойчиво преобразующую, активно созидательную и самосозидательную активность личности. Аналитико-рефлексивные умения имеют первостепенное значение.

Технологическая готовность находится на высоком уровне, и все компоненты технологической готовности тесно коррелируют. Педагогическая импровизация, педагогическая интуиция, воображение в деятельности педагога занимают важное место и способствуют решению педагогических задач.

В структуре личности гармонично сочетаются научные и педагогические интересы и потребности. Преподаватели заинтересованно относятся к различным способам повышения педагогического мастерства и педагогической культуры. Нередко они сами оказываются инициаторами повышения квалификации, охотно делятся своим опытом и активно перенимают опыт коллег, их отличает стремление совершенствоваться. Инновационная культура как многомерное явление, сложная социально-психологическая и педагогическая реальность включает следующие интегративные образования: психологическую и педагогическую культуру личности педагога, профессионально-психологическую компетентность, культуру профессионального поведения.

Методическими целями формирования инновационной культуры студентов в вузе являются следующие:

- овладение обучающимися теоретическими основами психолого-педагогических знаний по курсам «Психология» и «Педагогика»;

- разработка комплекта методического сопровождения курса «Английский язык» с учётом психолого-педагогического наполнения;

В системе методических, организационных средств повышения уровня инновационной культуры студентов в вузе нами были выделены в качестве наиболее эффективных следующие условия:

- демократические, диалоговые способы взаимодействия педагога и обучающихся (партисипативный подход к построению педагогического общения);

- вариативность в применении различных педагогических технологий с использованием инновационных активных методов организации учебного процесса в вузе;

- технология педагогического проектирования как инновационный метод управления педагогическими системами и инструмент педагогического прогнозирования ${ }^{1}$

При проектировании и разработки комплекта методического обеспечения, выполнении групповых, творческих заданий, профессионально-рефлексивных, деловых игр в сфере профессиональной деятельности принимали во внимание данные об уровне знаний, познавательных интересах, мотивации обучаемых, которые необходимо диагностировать на начальных этапах педагогического планирования. В ряду задач, которые удалось решить в процессе обучения студентов в рамках занятиях по английскому языку, важнейшими были следующие:

- актуализация теоретических основ психолого-педагогической деятельности, необходимой как эффективного межличностного профессионального общения, управления человеческими ресурсами, осуществления различных видов профессиональной деятельности;

- освоение способов ведения содержательного диалога в процессе учебного взаимодействия с целью переноса сформированных умений в сферу профессиональной деятельности в перспективе;

- развитие подсистем инновационной культуры студентов (аксиологической, когнитивной, технологической, коммуникативной, регулятивной), позволяющих осуществлять в будущей профессиональной деятельности управление человеческими ресурсами, осуществление коммуникативной и педагогической деятельности как видов профессиональной деятельности.

• выявление наиболее важных подсистем инновационной культуры, требующих особого внимания в профессиональной подготовке и обучении.

Результаты исследования. Проанализировав отбор содержания по учебной дисциплине «Английский язык» для студентов 1, 2 курсов факультета «Иностранные языки» в Каракалпакском государственном университете пришли к выводу, что в процессе изучения английского языка студенты от освоения понятийной базы изучаемой специальности переходят к более творческим заданиям, требующим не столько усвоения знания, сколько овладения

1 Ляшенко М.С. Научно-теоретические основы формирования психолого-педагогической культуры у студентов в вузе. -М., 2010. -156 С. 
способами и средствами деятельности, необходимыми для их профессиональной самореализации в будущем. В течение всего периода обучения наблюдается переход от репродуктивных форм работы, предполагающих освоение теоретических текстов и овладение общей терминологией, необходимой для профессионального общения к творческому этапу, рассматривающему как цели обучения формирование активной творческой личности, стремящейся к самосовершенствованию во всех сферах жизнедеятельности.

Качество обучения специалистов во многом определяется наличием комплекта методического обеспечения учебного процесса. В нашем исследовании комплект методического обеспечения включает в себя рабочие программы, модули учебных занятий, тексты лекций, авторские учебно-методические пособия, дидактические, демонстрационные материалы, сценарии деловых игр и т. д. Профессиональная направленность обеспечивается отбором содержания обучения, программой дисциплины, тематическими планами. Программа дисциплины включает в себя тематический план, отражающий содержание дисциплины, базовый учебник, терминологический словарь, формы контроля студентов (текущие, итоговые, аттестационные), тематику заданий по различным формам контроля, вопросы для оценки качества освоения дисциплины ${ }^{1}$.

Повышение эффективности учебных занятий по английскому языку происходит за счет использования активных методов обучения, позволяющих непосредственно вовлечь студентов в образовательный процесс. К таким методам, применяемым на занятиях по английскому языку относятся: деловые игры, разбор практических примеров (кейс- стадии), ролевые игры, групповые дискуссии, психолого-педагогические тренинги, авторские методические разработки и т.п. Активное применение данного инструментария в рамках практических занятий по английскому языку проиллюстрировать взаимосвязь изучаемой темы с ранее изученным материалом, закрепить пройденный материал, формировать все подсистемы инновационной культуры будущих учителей английского языка.

Для освоения психолого-педагогической деятельности будущему специалисту необходимо владеть практическими умениями и навыками, процедурами тренинга и оценки, способами самооценки, приемами развития педагогической техники. На практических занятиях по английскому языку, где предполагается работа в парах, малых группах, и самостоятельно необходимо использовать возможности имитационных технологий, предполагающих введение в вузовский учебный процесс видов, форм, методов деятельности, в большей или меньшей степени имитирующих будущую профессиональную деятельность. Важность применения имитационных технологий отмечается также в ряде исследований учёных. Данные технологии позволяют ввести обучаемых в контекст рассматриваемой проблемы или задачи, знакомят их со способами ее решения на конкретных примерах. Это играет важную роль в подготовке будущих специалистов, так как позволяет студентам получать необходимые компетенции, развивает мышление, творческий потенциал. Студенты совершенствуют не только свои речевые навыки посредством коммуникации на английском языке во время обсуждения проблемы, но и приобщаются к культуре общения, ведения делового спора, стратегиям медиации в формальной дискуссии.

Рассмотрим приём использования ролевых игр как пример имитационных игровых активных методов работы. Использование данного активного метода организации учебнопознавательной деятельности студентов помогает решить преподавателю ряд задач: апеллирование к мотивационной системе в структуре личности за счёт создания интереса к игровым формам работы и усиления личностной сопричастности к происходящему в ролевой игре; формирование учебного сотрудничества и партнерства; систематизация знаний по пройденной теме; возможность совместного принятия решения по поставленной в ролевой игре проблеме; развитие и совершенствование умений и навыков, формируемых в рамках дисциплины и др. В основе ролевой игры лежит организованное речевое общение обучающихся в соответствии с распределёнными между ними ролями и игровым сюжетом. Данное общение может быть управляемое или нет преподавателем исходя из уровня языковой подготовки студентов. Основой эффективно проведенной ролевой игры является культура общения и поведения, предполагающая достаточно высокий уровень психологопедагогической культуры, проявляющейся в адекватной положительной «Я-концепции», творческом подходе к решаемой задаче, знании психолого-педагогический технологий

\footnotetext{
${ }^{1}$ Беспалько В. П. Слагаемые педагогической технологии. - М.:Педагогика, 1989. - 190 с.
} 
владения и управления собой и умением оказывать влияние на других, речевом этикете и такте, способности продуктивно сотрудничать в группе, эффективно применять накопленные знания и умения при принятии решений и готовность нести ответственность за последствия.

Рассмотрим применение ролевой игры, разработанного с целью обсуждения различных возможностей профессионального роста и саморазвития в вузовском и послевузовском образовании, а также возможностей трудоустройства, карьерного продвижения. Студентам предлагается ряд ролей: молодой рабочий, думающий о получении высшего образования; преподаватель, рассматривающий перспективы перехода на административную должность; специалист среднего возраста, задумавшийся о курсах повышения квалификации; представитель департамента труда местной администрации; работодатель; работник службы занятости населения; студент-отличник; консультант-психолог; сотрудник предпенсионного возраста. Каждая роль схематично обозначена и требует предварительной подготовки. Определена также и принципиальная позиция участника ролевой игры. В ходе игры студенты, используя знания по пройденной теме, индивидуальный жизненный опыт, дополнительный материал (без или под руководством преподавателя: его роль определена как ведущий) стараются найти ответ на вопрос: «Как адаптироваться к меняющимся рыночным условиям и стать востребованным успешным работником на рынке труда?».

Такие задания требуют от обучаемых активизации их творческого, интеллектуального, эмоционально-нравственного потенциала, способствуют повышению инновационной культуры за счет включения всех подсистем данного системного образования в процессе образовательной деятельности. Активные методы обучения позволяют удовлетворить не только интеллектуальные потребности студентов, но и коммуникативно-деятельностные потребности, возникающие при речевом развитии личности. Психолого-педагогические знания и умения сопровождают удовлетворение этих потребностей, так как без психологопедагогических знаний и умений невозможно эффективно общаться и оказывать педагогическое воздействие. Данные упражнения направлены на формирование положительной мотивации к профессиональной деятельности, апеллируют к доминирующим мотивам инструментальной мотивации: профессиональным, академическим, коммуникативным, когда язык воспринимается как средство развития профессиональнообразовательной подсистемы, инструментом приобщения к научному знанию ${ }^{1}$. Разработанные и адаптированные с учётом специфики преподавания английского языка задания имитационного характера повышают мотивационно-ценностное отношение к будущей профессии и формируют позитивному отношению к себе (аксиологический компонент). Коммуникация происходит на английском языке, и студенты учатся культуре аргументации, приемам активного слушания, выражения согласия и несогласия по отдельным пунктам (коммуникативный компонент); рефлексия на конечном этапе способствует развитию регулятивной подсистемы психолого-педагогической культуры.

Становление личности будущего специалиста во многом определяется профессиональной направленностью личности (аксиологический компонент). Наиболее активной её формой является склонность, выступающая как потребность в определенной деятельности. Представляя собой систему мотивов, направленность способствует формированию определенных способностей. Следовательно, необходимо использовать такой вид заданий, которые бы формировали бы направленность на профессиональную деятельность, и в итоге способствовали бы росту психолого-педагогической культуры через аксиологическую и профессионально-образовательную подсистемы.

В предлагаемой нами методике важными элементами формирования культуры студентов в процессе изучения английского языка являются интересы, жизненный установки и ценности, индивидуально-личностные потребности, то есть аксиологический компонент психолого-педагогической культуры. У специалистов, работающих в группе профессий «человек-человек» сформированность аксиологического компонента определяется как умением выстраивать эмоциональные отношения с сотрудникам, так и направленностью личности, оказывая влияние на познавательные потребности и являясь источником мотивации, успешности не только в учебной деятельности, но и в профессиональной карьере в будущем

\footnotetext{
${ }^{1}$ Минеева О. А., Даричева, М. В. Использование системы Moodle в процессе обучения иностранному языку студентов неязыковых специальностей.// Вектор науки Тольяттинского государственного университета. Серия: Педагогика, психология, 2015, (4(23).
} 
Развитие системы инновационной культуры студентов требует от педагогической науки и практики изучения и внедрения новых методов их обучения и воспитания. Инновации в педагогике связаны с общими процессами в обществе, глобальными проблемами, интеграцией (лат. Integratio - восстановление, объединение в целое отдельных элементов) знаний и форм социального бытия. Сейчас создаётся новая педагогика, характерным признаком которой является инновационность - способность к обновлению, открытость новому.

Известно, что инновационный процесс - это комплексная деятельность по созданию, усвоению, использованию и распространению новшеств. Для того, чтобы вызвать интерес у учащихся к изучению английского языка, мы, преподаватели английского языка, должны искать новые инновационные формы и методы обучения. Во время учебы нужно использовать такие методы, при которых:

• у студентов возникает желание к творческой, результативной работе;

- студенты становятся активными, раскованными, пытаются добиться успеха.

Специфика английского языка как учебного предмета заключается в том, что общение является не только конечной целью обучения, но и средством её достижения. Именно преподаватель делает всё возможное и невозможное для этого.

Поскольку речь остаётся единственной универсальной базой мышления, знание английского языка следует рассматривать с точки зрения совершенствования интеллектуальных способностей (памяти, воображения, критического, логического, креативного мышления). Творчество является высшим проявлением развития человеческого разума. Творческая способность - это способность удивляться и познавать, умение находить решения в нестандартных ситуациях, это нацеленность на открытие нового и способность глубокого осознания своего опыта. Благодаря творческой деятельности у обучающегося развивается способность самостоятельно реализовать свои возможности, самореализация ведёт к личностному росту.

Реализация этой идеи невозможна без разработки и внедрения соответствующих технологий обучения. ВУЗ не должен быть подготовкой к жизни, вуз должен быть жизнью. Достичь этого можно за счёт инновационного подхода, создавая интерактивную среду. Слово интерактив (перевод с английского inter - «взаимный», act - «действовать») означает взаимодействие. Интерактивный метод - это способ взаимодействия с учениками через беседу, диалог.

Интерактивное обучение - это обучение в режиме диалога, во время которого происходит взаимодействие участников педагогического процесса с целью взаимопонимания, совместного решения учебных задач, развития личностных качеств студентов. Современному преподавателю важно знать новейшие методы преподавания английского языка, специальные учебные технологии и приемы, чтобы оптимально подобрать тот или иной метод преподавания в соответствии с уровнем знаний, потребностей и интересов студентов. Рациональное и мотивированное использование методов обучения на занятиях по английскому языку требует креативного подхода со стороны преподавателя.

Качественная языковая подготовка студентов невозможна без использования современных инновационных образовательных технологий. Современные инновационные технологии в образовании - это использование информационных и коммуникационных технологий в обучении, занятость в обучении, работа с учебными компьютерными и мультимедийными программами, дистанционные технологии в обучении иностранным языкам, создание презентаций в программной среде Microsoft PowerPoint, использование ресурсов всемирной сети Интернет. Эти технологии обеспечивают индивидуализацию и дифференциацию обучения с учётом способностей студентов, их уровня знаний.

Для достижения коммуникативной компетенции - коммуникативных умений, сформированных на основе языковых знаний, навыков и умений - я использую новейшие методы обучения, сочетающие коммуникативные и познавательные цели.

Инновационные методы обучения английскому языку, основанные на инновационном подходе, направленны на развитие и самосовершенствование личности, на раскрытие ее резервных возможностей и творческого потенциала.

Основными принцами современных методов являются: движение от целого к частному, ориентация занятий на студента, целеустремленность и содержательность занятий, их направленность на достижение социального взаимодействия при наличии веры преподавателя в успех своих студентов, интеграция языка и усвоение ее посредством знаний из других областей наук.

Современная коммуникативная методика предлагает широкое внедрение в учебный процесс активных нестандартных методов и форм работы для лучшего сознательного усвоения 
материала. На практике достаточно эффективными оказались такие формы работы: индивидуальная, парная, групповая и работа в команде.

К современным технологиям относится технология сотрудничества, которая активно внедряется в учебный процесс. Основная идея заключается в создании условий для активной совместной деятельности студентов в различных учебных ситуациях. Студенты объединяются в группы по 3-4 человека, им дают одну задачу, при этом обсуждают роль каждого. Каждый студент отвечает не только за результат своей работы, но и за результат всей группы. Поэтому слабые студенты стараются выяснить у сильных то, что им непонятно, а сильные - чтобы слабые разобрались в задании. И от этого выиграет вся группа, так как совместно ликвидируют пробелы в знаниях.

Во время различных видов работы студенты становятся перед проблемой пополнения знаний, лексического запаса или коммуникативных умений, поэтому они активизируют свою деятельность и в процессе общения пытаются решить данные вопросы. Это положительно влияет на развитие мышления и внимательности студентов, заинтересовывает их и стимулирует к сотрудничеству.

Поэтому все упражнения и задачи должны быть коммуникативно оправданными дефицитом информации, выбором и реакцией (Information gap, choice, feedback). Для их выполнения студенту потребуется дополнительная информация и приложить определенные усилия для её достижения и таким образом смогут лучше и эффективнее организовать свою деятельность.

Наиболее эффективны формы парной и групповой работы:

- внутренние (внешние) круги (inside / outside circles);

- мозговой штурм (brain storm);

- чтение зигзагом (jigsaw reading);

- обмен мнениями (think-pair-share);

- парные интервью (pair-interviews) и другие.

Эти формы работы способствуют расширению знаний и умений студентов. В процессе общения студенты учатся решать сложные задачи на основе анализа соответствующей информации, выражать альтернативные мнения, принимать взвешенные решения, общаться с разными людьми, участвовать в дискуссиях.

Одной из технологий, обеспечивающей личностно-ориентированное обучение, является метод проектов как способ развития творческой, познавательной деятельности, самостоятельности. Проекты могут подразделяться на монопроекты, коллективные, устноязыковые, письменные и Интернет-проекты. Работа над проектом - это многоуровневый подход к изучению языка, охватывающая чтение, аудирование, говорение и грамматику. Метод проектов способствует развитию активного самостоятельного мышления у учащихся и ориентирует их на совместную исследовательскую работу. По моему мнению, проектное обучение актуально тем, что учит детей сотрудничеству, воспитывает такие этические ценности, как взаимопомощь и умение сопереживать, формирует творческие способности и активизирует учащихся.

Важным средством инновационного обучения является также использование мультимедийного комплекса (МК) в составе интерактивной доски, персонального компьютера и мультимедийного проектора. Такой комплекс сочетает все преимущества современных компьютерных технологий и выводит процесс обучения на качественно новый уровень. Благодаря наглядности и интерактивности МК позволяет мне привлечь весь класс к активной работе.

Использование интерактивной доски на уроке значительно увеличивает эффективность обучения учащихся в школе.

Были определены ключевые направления применения МК:

- презентации, демонстрации и моделирования ситуаций;

- повышение активности учащихся на уроке;

- увеличение темпа урока.

Итак, МК предоставляет уникальные возможности для работы и творчества при значительной легкости в управлении. Необходимо учитывать важный психологический момент: современные студенты, у которых дома имеются компьютеры с многочисленными играми и телевизоры, привыкают воспринимать это как нечто обычное. Возможности МК позволяют переключить студентов на понимание того, что видео и игровые программы успешно используются для обучения, способствуют развитию творческой активности, увлечению предметом, созданию лучших условий для освоения навыков аудирования и 
говорения, что обеспечивает, в конце концов, эффективность усвоения материала на уроке английского языка.

Считаем, что использование МК на занятиях позволяет активно привлекать студентов в учебный процесс, увеличивает мотивацию обучения, стимулирует творческую активность и способствует развитию личности студента, расширяет возможности представления учебной информации, оно является наиболее эффективным и экономным по времени, помогает студентам подготовиться к сдаче тестов, экзаменов. МК является мощным инструментом, который может быть приспособлен для использования в изучении английского языка с широким диапазоном тем.

Можно выделить следующие преимущества инновационного обучения:

- установление дружеской атмосферы и взаимосвязей между участниками общения;

- студенты могут быть более независимыми и уверенными в себе;

- преподаватель поощряет студентов к сотрудничеству, подбадривает их, они не боятся допускать ошибки;

- студенты могут преодолеть страх перед языковым барьером;

- преподаватель не доминирует;

- слабые студенты могут получить помощь от более сильных;

• каждый студент, привлеченный к работе, имеет определённую задачу;

- студенты могут использовать свои знания и опыт, приобретенный ранее.

Выводы. Таким образом, обучение английскому языку языкам будет эффективным именно благодаря комплексному применению средств новейших инновационных технологий и зависит от способности преподавателя применять гуманистический подход к обучению.

Методы обучения английскому языку, основанному на гуманистическом подходе, помогают раскрыть творческий потенциал студентов и способствуют их развитию и совершенствованию во время учебно-коммуникативного процесса.

Исходя из личного опыта, можно констатировать, что процесс обучения - это не автоматическое вложение учебного материала в голову студента. Он требует напряжённой умственной работы студента и его активного участия в этом процессе.

Преподаватель достигнет успеха только тогда на своих занятиях, когда поймёт, что студентам нравится всё новое и интересное. Мы, преподаватели, должны помнить, что одна и та же модель проведения занятий, не даёт возможности студентам раскрыть себя полностью, останавливает развитие творческого потенциала обучения.

Таким образом, преподаватель вуза - не только профессия, суть которой передавать знания, но и высокая миссия сотворения личности, утверждения человека в человеке. Инновационное мастерство каждого специалиста уникально и неповторимо, как неповторима сама личность преподавателя.

\section{ЛИТЕРАТУРА}

1. Указ Президента Республики Узбекистан № УП-5847 от 20 апреля 2019 года «Об утверждении Концепции развития системы высшего образования Республики Узбекистан до 2030 года». www.lex.uz.

2. Бочкарева Т. С. Мультидисциплинарные дидактические комплексы как средство формирования инновационной культуры студентов вузов:дис... канд. пед. наук. - Тольятти, 2008. - 224 с.

3. Беспалько В. П. Слагаемые педагогической технологии. - М.:Педагогика, 1989. - 190 с.

4. Беспалько В. П. Стандартизация образования: основные идеи и понятия // Педагогика. - 1993. - № 5. - С. 16-25.

5. Галажинский Э. В. Справка. Инновационный потенциал личности: содержание, структура, пути развития // http://www.raop.ru/content/Otdelenie_psihologii_i_fiziologii.2011.06.15.Spravka.pdf (Дата обращения: 20 марта 2016 г.).

6. Гоулман Д., Бояцис Р., Макки Э. Эмоциональное лидерство. Искусство управления людьми на основе эмоционального интеллекта. - М.:Альпина Паблишер, 2015. - $301 \mathrm{c}$.

7. Делия В. П. Инновационное мышление в XXI веке. - Балашиха:Де-По. 2011. - 228 с.

8. Минеева, О. А., Даричева, М. В. Использование системы Moodle в процессе обучения иностранному языку студентов неязыковых специальностей.// Вектор науки Тольяттинского государственного университета. Серия: Педагогика, психология, 2015, (4(23). 